\title{
Quality is the key for emerging issues of population-based colonoscopy screening
}

\author{
Jin Young Yoon ${ }^{1}$, Jae Myung Cha ${ }^{1}$, Yoon Tae Jeen ${ }^{2}$, on behalf of Medical Policy Committee of \\ Korean Association for the Study of Intestinal Diseases (KASID), Quality Improvement Committee of \\ Korean Society of Gastrointestinal Endoscopy (KSGE) \\ ${ }^{1}$ Division of Gastroenterology, Department of Internal Medicine, Kyung Hee University Hospital at Gangdong, Kyung Hee University School of \\ Medicine, Seoul, ${ }^{2}$ Division of Gastroenterology, Department of Internal Medicine, Korea University Anam Hospital, Korea University College of \\ Medicine, Seoul, Korea
}

Colonoscopy is currently regarded as the gold standard and preferred method of screening for colorectal cancer (CRC). However, the benefit of colonoscopy screening may be blunted by low participation rates in population-based screening programs. Harmful effects of population-based colonoscopy screening may include complications induced by colonoscopy itself and by sedation, psychosocial distress, potential over-diagnosis, and socioeconomic burden. In addition, harmful effects of colonoscopy may increase with age and comorbidities. As the risk of adverse events in population-based colonoscopy screening may offset the benefit, the adverse events should be managed and monitored. To adopt population-based colonoscopy screening, consensus on the risks and benefits should be developed, focusing on potential harm, patient preference, socioeconomic considerations, and quality improvement of colonoscopy, as well as efficacy for CRC prevention. As suboptimal colonoscopy quality is a major pitfall of population-based screening, adequate training and regulation of screening colonoscopists should be the first step in minimizing variations in quality. Gastroenterologists should promote quality improvement, auditing, and training for colonoscopy in a population-based screening program. (Intest Res 2018;16:48-54)

Key Words: Colonic neoplasms; Colonoscopy; Quality; Safety; Screening

\section{INTRODUCTION}

The incidence of colorectal cancer (CRC) in Korea has markedly increased in recent years. According to a report of the Korea Central Cancer Registry in 2014, CRC is the third most common type of cancer in both men and women. CRC accounts for $14.3 \%$ of 10 major cancers in Korean men (44 patients per 100,000 subjects) and $10.4 \%$ of 10 major can-

Received December 16, 2017. Revised December 19, 2017.

Accepted December 19, 2017.

Correspondence to Yoon Tae Jeen, Division of Gastroenterology,

Department of Internal Medicine, Korea University Anam Hospital, Korea University College of Medicine, 73 Inchon-ro, Seongbuk-gu, Seoul 02841,

Korea. Tel: +82-2-920-6555, Fax: +82-2-953-1943, E-mail: ytjeen@korea. ac.kr

*This article is co-published by the Intestinal Research, Clinical Endoscopy, and Korean Journal of Gastroenterology for facilitated distribution. cers in Korean women (24 patients per 100,000 subjects). ${ }^{1}$ This indicates that the incidence of CRC in Korea is comparable to that in Western countries. In Korea, mortality rates for CRC in 2015 were $9.9 \%$ in men, representing the fourth most common cause of cancer-related death, and $12.3 \%$ in women, the second most common cause of cancer-related death. $^{1}$

Most CRC arises from adenomatous polyps that progress from small to large size and then to cancer. The slow transition from polyp to CRC in most patients allows opportunities to prevent development of CRC and CRC-related death by removing precancerous lesions. Many countries have started CRC screening programs; however, screening modalities and strategies differ among countries. ${ }^{2-4}$ In Korea, the National Cancer Screening Program (NCSP) for CRC provides a single annual fecal occult blood test (FOBT) for

\footnotetext{
๑ Copyright 2018. Korean Association for the Study of Intestinal Diseases. All rights reserved.

This is an Open Access article distributed under the terms of the Creative Commons Attribution Non-Commercial License (http://creativecommons.org/licenses/by-nc/4.0)

which permits unrestricted non-commercial use, distribution, and reproduction in any medium, provided the original work is properly cited.
} 
adults aged $\geq 50$ years, with secondary confirmatory colonoscopy for those with positive FOBT results since 2004. ${ }^{5,6}$ FOBT is a more efficient modality for population-based screening owing to greater preference, convenience, low risk, and low cost. ${ }^{4,7}$ Meanwhile, the advantages of screening colonoscopy include visualization of the entire colon, removal of precancerous or early CRCs in a single step, and longer screening intervals of up to 5 to 10 years. ${ }^{8,9}$ Because of these advantages, the preference for colonoscopy as a population-based CRC screening tool has continued to increase. Several Western countries such as Austria, Germany, and Poland use colonoscopy in population-based screening. ${ }^{10-12}$ Therefore, the adoption of colonoscopy as a population-based screening tool has been advocated in Korea. ${ }^{13}$

In this context, we reviewed the benefits and harms of population-based colonoscopy screening and discuss the prerequisites for screening in Korea.

\section{BENEFITS OF SCREENING COLONOSCOPY}

Several studies have evaluated the effectiveness of screening colonoscopy in average risk individuals. Until now, indirect data have been derived from observational or cohort studies. Case-control studies have demonstrated reductions in CRC incidence of up to $70 \%$ after initial screening colonoscopy, ${ }^{14,15}$ and a cohort study found a $76 \%$ to $90 \%$ reduction in CRC incidence after polypectomy. ${ }^{11}$ A meta-analysis of 6 observational studies of colonoscopy suggested a 40\% to $60 \%$ reduction in CRC incidence. ${ }^{16}$ A cohort study found that a history of a screening colonoscopy greatly reduced the risk of CRC incidence (adjusted OR, 0.09). ${ }^{17}$ A populationbased case-control study reported $30 \%$ reduction in CRCrelated mortality. ${ }^{18}$ In addition, there was a $53 \%$ reduction in CRC mortality in patients who underwent polypectomy for adenomas compared to that in the general population. ${ }^{16} \mathrm{Co}-$ hort studies showed that colonoscopy and polypectomy reduced CRC-related mortality by approximately $65 \% .{ }^{19}$ These non-randomized case-control and cohort studies in averagerisk population have consistently demonstrated a reduction in CRC incidence and mortality. However, no published randomized trials have demonstrated the effectiveness of colonoscopy by preventing CRC development and reducing mortality.

Furthermore, the benefits of colonoscopy should be cautiously interpreted, because major evidence of benefits was based on secondary colonoscopic examinations for subjects with a positive FOBT or abnormal sigmoidoscopy, ${ }^{20}$ and these studies may be biased by potentially confounding variables. In addition, the mortality reduction from colonoscopy may not be significantly different from that of FOBT or sigmoidoscopy, since the efficacy of screening must be compared with consideration of participation rates and the convenience of each screening test. For example, in a randomized, controlled trial performed in Spain, ${ }^{10}$ subjects in the FOBT group were more likely to participate in screening than were those in the colonoscopy group (34.2\% for FOBT vs. $24.6 \%$ for colonoscopy, $P<0.001)$. As a result, the number of subjects in whom CRC was detected was similar in the FOBT and colonoscopy groups $(0.1 \%$ in the FOBT group vs. $0.1 \%$ in the colonoscopy group, $P=0.99$ ). Since the primary outcome of this trial is the reduction in the mortality rate from CRC at 10 years, the relative benefits and risks of the 2 strategies will be assessed at the end of the trial. However, the most relevant result of this interim analysis is that onetime FOBT screening is very similar to one-time colonoscopy with respect to the CRC detection rate, with no significant difference in the stage of tumors detected by the 2 strategies.

In another study from the United States, ${ }^{21}$ participants who were recommended to have colonoscopy completed screening at a significantly lower rate $(38 \%)$ than those who were recommended to have FOBT $(67 \%)(P<0.001)$, or those given a choice between FOBT or colonoscopy $(69 \%)(P<0.001)$. These results suggest that patient preferences should be considered for CRC screening recommendations. In the U.S. study comparing the effectiveness of FOBT outreach and colonoscopy outreach to increase screening participation, rates were higher with mailed FOBT outreach (58.8\%) and mailed colonoscopy outreach (42.4\%) than with usual care using opportunistic visit-based screening $(29.6 \%)(P<0.001$ for both). In this study, FOBT-based outreach was found to be more effective than colonoscopy-based outreach to increase one-time screening participation; however, the effectiveness of outreach strategies for promoting completion of the entire screening process may be different in Korea. FOBT, sigmoidoscopy, and colonoscopy ultimately had similar (20\%-25\%) effectiveness in reducing CRC mortality, with $59 \%$ to $90 \%$ adherence and $25 \%$ to $37 \%$ CRC mortality reduction for FOBT, ${ }^{22-24} 32 \%$ to $65 \%$ adherence and $43 \%$ to $59 \%$ CRC mortality reduction for sigmoidoscopy, ${ }^{25-27}$ and $10 \%$ to $60 \%$ adherence and $65 \%$ to $69 \%$ CRC mortality reduction for colonoscopy. ${ }^{14,19,28,29}$

Finally, health-conscious individuals may be more likely to undergo screening colonoscopy in case-control studies, leading to overestimation of the beneficial effect of screening colonoscopy in observational studies. Therefore, the efficacy of primary colonoscopy screening can only be estimated by 
a randomized controlled study, which is similar to a population-based study. Since 2009, 3 large randomized controlled trials have been evaluating the effectiveness of screening colonoscopy for reduction of CRC incidence and mortality in the United States and Europe, and it is expected that the results will be available in the 2020s. . $^{10,30,31}$ Two trials are comparing the effect of one-time screening colonoscopy and FOBT annually or biennially, ${ }^{10,30}$ while a Nordic-European trial is comparing the effect of screening colonoscopy versus no screening. ${ }^{31}$

\section{SAFETY OF SCREENING COLONOSCOPY}

Focus on the safety of screening colonoscopy is essential. Although most authors concluded that colonoscopy is a safe procedure, data on the complication rate in populationbased screening colonoscopy are limited. Most previous studies were analyzed based on a small number of patients or a large sample of administrative data, which may frequently lack detail and can be less appropriate for identification of complications. ${ }^{32}$ Furthermore, because colonoscopic complication rates are very low (about $0.1 \%$ ), a 5 -fold increase in complication rates would require a sample size of more than 5,000 to demonstrate a significant difference with a statistical power of $80 \%$. Therefore, the risk of screening colonoscopy in the literature may be underpowered due to a small sample size.

Harmful effects of colonoscopy screening programs include complications induced by colonoscopy itself, followed by those due to therapeutic procedures, sedation, psychosocial distress, potential over-diagnosis, and national socioeconomic burden. Colonoscopy is an invasive tool with an appreciable rate of various complications. In a recent published systematic review, the overall risk of major bleeding after colonoscopy was $0.8 / 1,000$ and that of perforation was $0.07 / 1,000 .^{33}$ Other complications from colonoscopy include cardiovascular events, postpolypectomy syndrome, vasovagal reactions, and abdominal pain or discomfort. ${ }^{33}$

In the National Endoscopic Database from the United States, serious events occurred in 3.4/1,000 patients within 30 days of screening and surveillance colonoscopy. ${ }^{34}$ In this study, gastrointestinal bleeding requiring hospitalization occurred in 1.59/1,000 examinations, perforations occurred in $0.19 / 1,000$, and postpolypectomy syndrome in $0.09 / 1,000$, with complications directly related to colonoscopy in $2.01 / 1,000$. Serious bleeding was reported $1.2 / 1,000$ patients aged 50 to 69 years in a population-based trial ${ }^{10}$ and 1.5/1,000 patients aged 55 to 64 years in the interim report of the Nordic-European initiative on CRC (NordICC) study. ${ }^{35}$ In addition, perforation was observed in $1 / 1,000$ examinations, bleeding owing to polypectomy in 140/1,000 $(0.14 \%)$, and postpolypectomy syndrome in $2 / 1,000$ in the NordICC study. It is very important to note that the rate of major complication was somewhat higher in the NordICC study, because this was a randomized clinical trial comparing colonoscopy screening or no screening in a populationbased screening setting. This means that the rate of major complications may be higher than previously anticipated in population-based colonoscopy screening, as colonoscopists of variable quality may perform examinations in a real world setting.

Elderly patients should be carefully considered for screening colonoscopy as the risks may increase with age and comorbidity. The rate of serious adverse gastrointestinal events in patients older than 65 years in the United States was $7 / 1,000$ patients, ${ }^{36}$ and the rate of unplanned hospital visits within 7 days was $16.3 / 1,000$ colonoscopies in the United States. ${ }^{37}$ In an age-matched analysis among those 66 to 69 years old, the rate of serious gastrointestinal events within 30 days of outpatient colonoscopy was significantly high at 5/1,000 (3.8-6.2/1,000 examinations), compared with $1.3 / 1,000(0.9-1.7 / 1,000)$ after outpatient clinic in a non-colonoscopy group. ${ }^{36}$ In a systematic review and metaanalysis of adverse events among those undergoing colonoscopy, cumulative gastrointestinal adverse events occurred in 26/1,000 examinations (including bleeding in 6.3/1,000 and perforation in $1 / 1,000$ ), cardiovascular and pulmonary adverse events in 19.1/1,000, and mortality in 1/1,000 examinations in patients aged 65 to 79 years. ${ }^{38}$ As patients older than 65 years of age had a higher risk of complications during and after colonoscopy, population-based screening should consider the potential for harm in elderly patients. For the planning of a population-based colonoscopy screening program, the risk and benefit balance should be tailored to individual participants, based on age and comorbidity. The increasing number of screening colonoscopies could lead to a dramatic increase in complications associated with CRC screening, especially in elderly patients.

\section{QUALITY OF SCREENING COLONOSCOPY}

Another issue is the quality of screening colonoscopy. Although colonoscopy effectively detects colorectal neoplasms and is even used to resect lesions, it is not a perfect modality, as demonstrated in studies based on tandem colonoscopy and computed tomographic colonography. ${ }^{39,40}$ Colonoscopy 
misses $6 \%$ to $12 \%$ of adenomas $1 \mathrm{~cm}$ or larger, ${ }^{40,41} 11 \%$ of advanced adenomas, ${ }^{42}$ and $5 \%$ of cancers. ${ }^{41,43}$ The overall miss rate for polyps of any size was $22 \%{ }^{44}$ and the miss rate for adenomas was $17.7 \%$ to $24.1 \%$ in a Korean study. ${ }^{45,46}$ Therefore, qualified colonoscopy is essential to decrease the miss rate. In a recent study with 223,842 patients undergoing 264,792 colonoscopies by 136 gastroenterologists, each $1 \%$ increase in ADR led the risk of interval CRC to 3\% decrease and that of fatal interval CRC to $5 \%$ decrease. ${ }^{47}$ In this study, patients of physicians in the highest ADR quintile had an adjusted risk of interval cancer of 0.52 (95\% CI, 0.39-0.69) compared with patients of physicians in the lowest ADR quintile. ${ }^{47}$ As the main purpose of a nationwide CRC screening program is to enhance early detection and reduce mortality, the effectiveness of screening is dependent upon the quality of baseline colonoscopy. A major finding of the NordICC study was that colonoscopy performance differed significantly among endoscopists; recommended benchmarks for cecal intubation $(95 \%)$ and adenoma detection (25\%) were not met by $17.1 \%$ and $28.6 \%$, respectively. ${ }^{35}$ In a population-based study from the Ontario cancer registry in Canada, 2 to $6 \%$ of CRCs were new or missed cancers (post-colonoscopy CRC, or PCCRC) detected within 6 to 36 months after colonoscopy. ${ }^{48} \mathrm{In}$ this study, colonoscopy performed by an internist or family physician or in a primary clinic was an independent risk factor for PCCRC. These population-based studies demonstrate a wide gap in quality among colonoscopists in realworld practice. A recent study also found that the sensitivity of colonoscopy for detecting adenomas and carcinomas is dependent on the experience and technique of the colonoscopist. $^{44}$

A large Canadian registry study ${ }^{49}$ showed that the endoscopist's specialty remained a significant predictor of missed cancers despite adjustment for procedural volume, indicating that even non-gastroenterologists with a high volume of procedures continue to miss more CRCs than gastroenterologists. Rabeneck et al. ${ }^{50}$ also showed that nongastroenterologists had a significantly higher rate of missed cancers than gastroenterologists, independent of procedural volume. There was also emerging evidence of a link between the endoscopist's specialty and colonoscopy quality in NCSP of Korea. ${ }^{51}$ No association between colonoscopy volume and missed caner may indicate that formal endoscopic training generally leads to competency in colonoscopy, contrasted with providers not receiving formal training who are unable to achieve competence despite the volume of procedures they perform. ${ }^{49-51}$ For the success of population-based screening colonoscopy by minimizing the variation of qual- ity between colonoscopists, adequate training and provider education for screening colonoscopists should be the first step in population-based colonoscopy screening.

To improve the performance of screening colonoscopy, documentation of quality indicators in population-based screening colonoscopy is essential..$^{52}$ Quality indicators from United States included informed consent, $\geq 97 \%$ cecal intubation rates, $\geq 85 \%$ adequate bowel preparation, $\geq 25 \%$ adenoma detection rate (ADR) (for men $\geq 30 \%$ ADR, for women $\geq 20 \% \mathrm{ADR}$ ), $\geq 6$ minutes average withdrawal time, and optimal level of complications $(<1 / 1,000$ perforation and $<1 \%$ post-polypectomy bleeding). It was reported that effort to obey withdrawal time of at least more than 6 minutes may be in correction performance of colonoscopists with subminimum ADRs. ${ }^{53}$ For the delivery of colonoscopy within the United Kingdom, key performance indicators should be aimed for all endoscopists. ${ }^{17}$ Key performance indicators included $\geq 97 \%$ unadjusted cecal intubation rates (minimum $90 \%$ ), $\geq 40 \%$ ADR (minimum 35\%), $\geq 95 \%$ adequate bowel preparation (minimum 90\%), $\geq 10$ minutes mean withdrawal time (minimum 6 minutes), $\geq 95 \%$ polyp retrieval rate (minimum $90 \%$ ), $<1 / 1,000$ perforation, $<1 \%$ post-polypectomy bleeding and $100 \%$ recording of comfort scores. ${ }^{17}$ As already demonstrated in NordICC study, suboptimal colonoscopy quality is a major pitfall in population-based colonoscopy screening. The ongoing NordICC study would demonstrate these influences on long-term outcomes of screening colonoscopy for the next decade. ${ }^{31,35}$

\section{COMPLIANCE OF SCREENING COLONOSCOPY}

Even though FOBT is a relatively simple, cheap and noninvasive tool, compliance with annual FOBT is below expectations. In a meta-analysis of prospective study for CRC screening, the overall participation rate for FOBT was only $42 \%{ }^{54}$ In an NCSP of Korea, FOBT participation rates were increased from approximately $20 \%$ in 2004 to $55 \%$ in 2016 . It was well-known that adherence to colonoscopy was commonly lower than for other screening tools. In a randomized clinical trial of competing strategies of CRC screening, 38\% participation of colonoscopy screening was significantly lower than $67 \%$ participation of FOBT screening. ${ }^{21}$ In a randomized controlled trial comparing one-time colonoscopy with biannual FOBT in Spain, the rate of participation was only $24.6 \%$ in the colonoscopy group, compared with $34.2 \%$ in the FOBT group $(P<0.001) .{ }^{10}$ In a recent German populationbased case-control study, ${ }^{17}$ only $1.7 \%$ of the patients with CRC underwent screening colonoscopy versus $12 \%$ of the 
patients without CRC. In a meta-analysis of prospective CRC screening studies of unselected populations, ${ }^{54}$ the overall participation rates for colonoscopy was only $28 \%$, compared with $42 \%$ for FOBT. In a survey from Korea, colonoscopy was preferred to FOBT at a ratio of 2.2 to $1(68.7 \%$ vs. $31.3 \%)$ for a primary CRC screening test by NCSP participants, however, it was limited as it was based on survey rather than clinical trial. ${ }^{13}$ The adoption of screening colonoscopy should be based on patient preference about screening methods, socioeconomic considerations, the current capacity to perform colonoscopy in each country, and its efficacy at preventing CRC. For the success of population-based colonoscopy screening, therefore, comprehensive information should be provided systematically to participants and subsequently result in enhancing participation rate to maximize the impact of national screening program.

\section{CURRENT ISSUES IN KOREA}

Performance of colonoscopy may be influenced by the endoscopist's specialty, ${ }^{44,48}$ however, no barrier exits for the performance of colonoscopy in the NCSP in Korea. Therefore, there is wide variation in performance level, experience level, and quality level among colonoscopists participating in the NCSP in Korea. Thus, quality improvement of screening colonoscopy is indeed an overarching theme in nationwide population-based colonoscopy screening in Korea. The volume of colonoscopy screening may be much improved by monitoring of key quality indicators, as it is known that quality feedback, with quarterly report cards, audits, external review, and video recordings could stimulate improvement in colonoscopy performance. ${ }^{55,56}$ Therefore, a nationwide registry system for screening colonoscopy should be developed and monitored.

In Korea, however, there is no monitoring system and no standard protocol on how to manage complications, ranging from mild (such as abdominal discomfort or pain) to serious (such as perforation or even death), during or after colonoscopy. As the balance of benefits and risks of colonoscopy screening may be changed with use of different definitions of complications, population-based screening should not minimize the risk by including all possible adverse events. For example, adverse events should include gastrointestinal, cardiovascular, and pulmonary adverse events associated with colonoscopy as well as sedation, and should also include adverse events associated with bowel preparation and socioeconomic loss from absenteeism. There has been no discussion or consensus on accountability for these adverse events, even for death, that may occur in healthy participants during screening colonoscopy. As the risk may offset the benefit, adverse events associated with colonoscopy screening should be properly managed and monitored.

\section{CONCLUSIONS}

To adopt population-based colonoscopy screening, consensus on the risks and benefits should be developed, focusing on potential harm, patient preference, socioeconomic considerations, and quality improvement of colonoscopy, as well as efficacy for CRC prevention. Ongoing randomized controlled trials may resolve these issues of colonoscopy screening; however, further research is needed, focusing on population-based colonoscopy screening in Korea. Gastroenterologists should promote quality improvement, auditing, and training for population-based colonoscopy screening.

\section{FINANCIAL SUPPORT}

The authors received no financial support for the research, authorship, and/or publication of this article.

\section{CONFLICT OF INTEREST}

No potential conflict of interest relevant to this article was reported.

\section{AUTHOR CONTRIBUTION}

Y.T.J., conceptualization; J.Y.Y, writing-original draft; J.M.C., writing-review \& editing.

\section{REFERENCES}

1. Causes of death statistics in 2016: incidence and mortality of cancer. Statistics Korea Web site. http://www.index.go.kr/potal/ main/EachDtlPageDetail.do?idx_cd=2770. Accessed Dec 26, 2017.

2. Schreuders EH, Ruco A, Rabeneck L, et al. Colorectal cancer screening: a global overview of existing programmes. Gut 2015;64:1637-1649.

3. van der Steen A, Knudsen AB, van Hees F, et al. Optimal colorectal cancer screening in states' low-income, uninsured populations: the case of South Carolina. Health Serv Res 2015;50:768-789. 
4. Gupta S, Halm EA, Rockey DC, et al. Comparative effectiveness of fecal immunochemical test outreach, colonoscopy outreach, and usual care for boosting colorectal cancer screening among the underserved: a randomized clinical trial. JAMA Intern Med 2013;173:1725-1732.

5. Shin A, Choi KS, Jun JK, et al. Validity of fecal occult blood test in the National Cancer Screening Program, Korea. PLoS One 2013;8:e79292. doi: 10.1371/journal.pone.0079292.

6. Yoo KY. Cancer control activities in the Republic of Korea. Jpn J Clin Oncol 2008;38:327-333.

7. Singal AG, Gupta S, Tiro JA, et al. Outreach invitations for FIT and colonoscopy improve colorectal cancer screening rates: a randomized controlled trial in a safety-net health system. Cancer 2016;122:456-463.

8. Wong MC, Ching JY, Chan VC, Sung JJ. The comparative costeffectiveness of colorectal cancer screening using faecal immunochemical test vs. colonoscopy. Sci Rep 2015;5:13568. doi: $10.1038 /$ srep 13568 .

9. Lee JL, Cha JM, Lee HM, et al. Determining the optimal surveillance interval after a colonoscopic polypectomy for the Korean population? Intest Res 2017;15:109-117.

10. Quintero E, Castells A, Bujanda L, et al. Colonoscopy versus fecal immunochemical testing in colorectal-cancer screening. N Engl J Med 2012;366:697-706

11. Brenner H, Stock C, Hoffmeister M. Effect of screening sigmoidoscopy and screening colonoscopy on colorectal cancer incidence and mortality: systematic review and meta-analysis of randomised controlled trials and observational studies. BMJ 2014;348:g2467. doi: 10.1136/bmj.g2467.

12. Stock C, Pulte D, Haug U, Brenner H. Subsite-specific colorectal cancer risk in the colorectal endoscopy era. Gastrointest Endosc 2012;75:621-630.

13. Cho YH, Kim DH, Cha JM, et al. Patients' preferences for primary colorectal cancer screening: a survey of the national colorectal cancer screening program in Korea. Gut Liver 2017;11:821-827.

14. Zauber AG, Winawer SJ, O'Brien MJ, et al. Colonoscopic polypectomy and long-term prevention of colorectal-cancer deaths. N Engl J Med 2012;366:687-696.

15. Nishihara R, Wu K, Lochhead P, et al. Long-term colorectalcancer incidence and mortality after lower endoscopy. N Engl J Med 2013;369:1095-1105.

16. Winawer SJ, Zauber AG, O’Brien MJ, et al. Randomized comparison of surveillance intervals after colonoscopic removal of newly diagnosed adenomatous polyps. The National Polyp Study Workgroup. N Engl J Med 1993;328:901-906.
17. Brenner H, Chang-Claude J, Jansen L, Knebel P, Stock C, Hoffmeister M. Reduced risk of colorectal cancer up to 10 years after screening, surveillance, or diagnostic colonoscopy. Gastroenterology 2014;146:709-717.

18. Brenner H, Chang-Claude J, Seiler CM, Rickert A, Hoffmeister M. Protection from colorectal cancer after colonoscopy: a population-based, case-control study. Ann Intern Med 2011;154:2230.

19. Kahi CJ, Imperiale TF, Juliar BE, Rex DK. Effect of screening colonoscopy on colorectal cancer incidence and mortality. Clin Gastroenterol Hepatol 2009;7:770-775.

20. Doubeni CA, Corley DA, Quinn VP, et al. Effectiveness of screening colonoscopy in reducing the risk of death from right and left colon cancer: a large community-based study [published online ahead of print October 12, 2016]. Gut. doi: 10.1136/gutjnl-2016-312712.

21. Inadomi JM, Vijan S, Janz NK, et al. Adherence to colorectal cancer screening: a randomized clinical trial of competing strategies. Arch Intern Med 2012;172:575-582.

22. Mandel JS, Bond JH, Church TR, et al. Reducing mortality from colorectal cancer by screening for fecal occult blood. Minnesota Colon Cancer Control Study. N Engl J Med 1993;328:13651371

23. Kronborg O, Fenger C, Olsen J, Jørgensen OD, Søndergaard O. Randomised study of screening for colorectal cancer with faecal-occult-blood test. Lancet 1996;348:1467-1471.

24. Hardcastle JD, Chamberlain JO, Robinson MH, et al. Randomised controlled trial of faecal-occult-blood screening for colorectal cancer. Lancet 1996;348:1472-1477.

25. Hol L, Wilschut JA, van Ballegooijen M, et al. Screening for colorectal cancer: random comparison of guaiac and immunochemical faecal occult blood testing at different cut-off levels. $\mathrm{Br}$ J Cancer 2009;100:1103-1110.

26. Hoff G, Grotmol T, Skovlund E, Bretthauer M; Norwegian Colorectal Cancer Prevention Study Group. Risk of colorectal cancer seven years after flexible sigmoidoscopy screening: randomised controlled trial. BMJ 2009;338:b1846. doi: 10.1136/ bmj.b1846.

27. Atkin WS, Hart A, Edwards R, et al. Uptake, yield of neoplasia, and adverse effects of flexible sigmoidoscopy screening. Gut 1998;42:560-565.

28. Citarda F, Tomaselli G, Capocaccia R, Barcherini S, Crespi M; Italian Multicentre Study Group. Efficacy in standard clinical practice of colonoscopic polypectomy in reducing colorectal cancer incidence. Gut 2001;48:812-815. 
29. Segnan N, Senore C, Andreoni B, et al. Comparing attendance and detection rate of colonoscopy with sigmoidoscopy and FIT for colorectal cancer screening. Gastroenterology 2007;132:2304-2312.

30. Dominitz JA, Robertson DJ. Colonoscopy versus fecal immunochemical test in reducing mortality from colorectal cancer (CONFIRM). U.S. National Library of Medicine Web site. http:// clinicaltrials.gov/ct2/show/study/NCT01239082. Accessed Dec 26, 2017.

31. Kaminski MF, Bretthauer M, Zauber AG, et al. The NordICC Study: rationale and design of a randomized trial on colonoscopy screening for colorectal cancer. Endoscopy 2012;44:695702 .

32. Denis B, Gendre I, Sauleau EA, Lacroute J, Perrin P. Harms of colonoscopy in a colorectal cancer screening programme with faecal occult blood test: a population-based cohort study. Dig Liver Dis 2013;45:474-480.

33. Vermeer NC, Snijders HS, Holman FA, et al. Colorectal cancer screening: systematic review of screen-related morbidity and mortality. Cancer Treat Rev 2017;54:87-98.

34. Ko CW, Riffle S, Michaels L, et al. Serious complications within 30 days of screening and surveillance colonoscopy are uncommon. Clin Gastroenterol Hepatol 2010;8:166-173.

35. Bretthauer M, Kaminski MF, Løberg M, et al. Population-based colonoscopy screening for colorectal cancer: a randomized clinical trial. JAMA Intern Med 2016;176:894-902.

36. Warren JL, Klabunde CN, Mariotto AB, et al. Adverse events after outpatient colonoscopy in the Medicare population. Ann Intern Med 2009;150:849-857.

37. Ranasinghe I, Parzynski CS, Searfoss R, et al. Differences in colonoscopy quality among facilities: development of a postcolonoscopy risk-standardized rate of unplanned hospital visits. Gastroenterology 2016;150:103-113.

38. Day LW, Kwon A, Inadomi JM, Walter LC, Somsouk M. Adverse events in older patients undergoing colonoscopy: a systematic review and meta-analysis. Gastrointest Endosc 2011;74:885896.

39. van Rijn JC, Reitsma JB, Stoker J, Bossuyt PM, van Deventer SJ, Dekker E. Polyp miss rate determined by tandem colonoscopy: a systematic review. Am J Gastroenterol 2006;101:343-350.

40. Pickhardt PJ, Nugent PA, Mysliwiec PA, Choi JR, Schindler WR. Location of adenomas missed by optical colonoscopy. Ann Intern Med 2004;141:352-359.

41. Rex DK, Cutler CS, Lemmel GT, et al. Colonoscopic miss rates of adenomas determined by back-to-back colonoscopies. Gastroenterology 1997;112:24-28.

42. Heresbach D, Barrioz T, Lapalus MG, et al. Miss rate for colorectal neoplastic polyps: a prospective multicenter study of backto-back video colonoscopies. Endoscopy 2008;40:284-290.
43. Bressler B, Paszat LF, Vinden C, Li C, He J, Rabeneck L. Colonoscopic miss rates for right-sided colon cancer: a populationbased analysis. Gastroenterology 2004;127:452-456.

44. Lin JS, Piper MA, Perdue LA, et al. Screening for colorectal cancer: updated evidence report and systematic review for the US Preventive Services Task Force. JAMA 2016;315:2576-2594.

45. Choi KY, Lee BI, Lee SY, et al. Colonoscopic miss-rate of colorectal polyp and adenoma. Korean J Gastrointest Endosc 2003;26:199-204.

46. Kim NH, Jung YS, Jeong WS, et al. Miss rate of colorectal neoplastic polyps and risk factors for missed polyps in consecutive colonoscopies. Intest Res 2017;15:411-418.

47. Corley DA, Jensen CD, Marks AR, et al. Adenoma detection rate and risk of colorectal cancer and death. N Engl J Med 2014;370:1298-1306.

48. Bressler B, Paszat LF, Chen Z, Rothwell DM, Vinden C, Rabeneck L. Rates of new or missed colorectal cancers after colonoscopy and their risk factors: a population-based analysis. Gastroenterology 2007;132:96-102.

49. Singh H, Nugent Z, Demers AA, Bernstein CN. Rate and predictors of early/missed colorectal cancers after colonoscopy in Manitoba: a population-based study. Am J Gastroenterol 2010;105:2588-2596.

50. Rabeneck L, Paszat LF, Saskin R. Endoscopist specialty is associated with incident colorectal cancer after a negative colonoscopy. Clin Gastroenterol Hepatol 2010;8:275-279.

51. Cha JM, Han DS, Lee HL, et al. Endoscopist specialty is associated with high-quality endoscopy in Korea. Yonsei Med J 2012;53:310-317.

52. Rex DK, Schoenfeld PS, Cohen J, et al. Quality indicators for colonoscopy. Gastrointest Endosc 2015;81:31-53.

53. Barclay RL, Vicari JJ, Greenlaw RL. Effect of a time-dependent colonoscopic withdrawal protocol on adenoma detection during screening colonoscopy. Clin Gastroenterol Hepatol 2008;6:1091-1098.

54. Khalid-de Bakker C, Jonkers D, Smits K, Mesters I, Masclee A, Stockbrügger R. Participation in colorectal cancer screening trials after first-time invitation: a systematic review. Endoscopy 2011;43:1059-1086.

55. Wong MC, John GK, Hirai HW, et al. Changes in the choice of colorectal cancer screening tests in primary care settings from 7,845 prospectively collected surveys. Cancer Causes Control 2012;23:1541-1548.

56. Rex DK, Hewett DG, Raghavendra M, Chalasani N. The impact of videorecording on the quality of colonoscopy performance: a pilot study. Am J Gastroenterol 2010;105:2312-2317. 